\title{
EFFECTS OF INNOVATION ON PRODUCTIVITY OF RUSSIAN FIRMS: DOES SIZE MATTER?
}

\author{
Oleg S. Mariev ${ }^{1}$, Andrey A. Pushkarev ${ }^{2}$
}

\begin{abstract}
The purpose of this study is to analyze the influence of a number of external factors on the productivity of individual enterprises in the Urals Federal District. As the main analysis tool, a panel regression with fixed effects at the firm level is used. The paper considers both Ural enterprises in general, and their individual subgroups, separated by their size.

The main results of the work are as follows. There is a positive impact of the number of patent applications per capita and technology imports on the company's productivity, with greater effects observed in medium sized firms, while in small and micro sized firms, the results are less significant. This, as well as the negative impact of spending on innovation on the dependent variable, may indicate an inadequate level of development of basic industries, which in turn slows the growth rates of all the companies, irrespective of their size. The obtained results are proposed to be used as a recommendation for the construction and improvement of the regional innovation policy.
\end{abstract}

JEL Classification Numbers: O31, H20; DOI: http://dx.doi.org/10.12955/cbup.v6.1179

Keywords: innovation, labor productivity, regional innovation policy, econometric analysis

\section{Introduction}

In many ways, the Russian innovation situation is unique. The Russian economy depends on mining and the sales of minerals, while the high technology share in the economy is low. Russia has a large potential for innovative development, which is the scientific legacy of the USSR, a high proportion of specialists with high education, as well as a large number of resources for the implementation of state projects. Nevertheless, intervention in innovation processes is necessary in order to create incentives for the private sector to participate in the innovations (Mariev \& Shorokhova, 2011)

This paper aims to uncover how different external effects of innovations and spatial characteristics affect the productivity of Russian firms. To better understand this problem, we employ statistical and econometric methods of analysis based on firm- and region-level data from Russian companies.

The rest of the paper is organized as follows. Section 2 provides a brief literature review. Section 3 provides a description of the data and methods used in this research. Section 4 discusses modelling outcomes based on the Russian region level innovation data and their policy implications. Section 5 concludes the paper.

\section{Literature review}

To find the most relevant factors that affect regional innovation activity for the empirical analysis we analyzed a number of papers that discuss similar problems. In this section, we will give a short summary of them. Modern research identifies a large number of potential factors that can influence the innovative development of a region. In order to organize a large number of available indicators, we divide them into several groups.

Researchers have carried out many studies confirming the positive impacts of innovation and an innovative climate on productivity. Examples of such works are Solow (1957), Griffith et al. (2006), Chudnovsky et al. (2006), and Masso and Vahter (2008), as well as a large number of empirical studies examining the examples of individual countries, industries and regions.

In addition, there are many studies pointing to the negative effects of innovation on firm productivity in the short and medium run (Raffo et al., 2008; Duguet, 2006; Janz et al., 2004; Lööf \& Heshmati, 2006). However, there is relatively less literature supporting this point of view and there is no unity of views on how innovation effects productivity. Which in many respects may also be due to the lack of consensus on which indicators can be used to assess innovation. In particular, many studies primarily focus on $\mathrm{R} \& \mathrm{D}$, not taking into account the specific features of innovative activities.

We also want to point out that there is a small number of Russian studies devoted to this problem, and even fewer of them use statistical, mathematical and econometric methods on the firm level.

\footnotetext{
${ }^{1}$ Graduate School of Economics and Management, Ural Federal University and Institute of Economics, Ural Branch of the Russian Academy of Sciences; Yekaterinburg, Russian Federation, o.s.mariev@urfu.ru

${ }^{2}$ Graduate School of Economics and Management, Ural Federal University, Yekaterinburg, Russian Federation, a.a.pushkarev@urfu.ru
} 
Summing up the review of the studies, it is worth noting that, although there is no consensus on the connection between innovation and productivity, research generally indicates that most of the indicators of innovation activity have a positive impact on productivity, but the degree of this influence varies considerably.

We present data and methodology of the econometric estimation in the next section.

\section{Data and econometric model}

For the econometric part of the study, the database Ruslana provided by Bureau Van Dijk is used. It contains accounting information for 27108 enterprises for the period from 2006 to 2015. Firms are located in all regions of the Urals Federal District of Russia and cover almost all the cities of the federal district, as well as a significant number of settlements, villages, and other small municipalities.

To carry out an econometric analysis, based on the current research described in the previous section, as well as a number of others (Berger, 2010; Fritsch \& Aamoucke, 2013; Zhang, 2015), the following model specification was chosen:

$$
\text { lprod }_{g, t}=\ln (t a)_{g, t}+\sum \text { INNOV }_{k, t}+\sum \text { HCAP }_{k, t}+\sum \text { CONTROL }_{k_{2}, t}+\text { Fixed Effects, }
$$

Where lprod $_{g, t}$ is the natural logarithm of the labor productivity of the company $\mathrm{g}$ in year $\mathrm{t}$;

$\ln (t a)_{g, t}$ is the natural logarithm of the total assets of company $\mathrm{g}$ in year $\mathrm{t}$;

$\sum I_{N N O V_{k, t}}$ is the vector of innovative indicators of region $\mathrm{k}$ in year $\mathrm{t}$, consisting of:

- import_tech_per_cap - import of technologies per capita (USD),

- patent_ap_per_cap - the number of patent applications per capita,

- innov_spend_per_cap - expenditure on innovation per capita (USD),

- innov_share - the share of enterprises involved in innovative activities;

$\sum H C A P_{k, t}$ - vector of human capital indicators of region $\mathrm{k}$ in year $\mathrm{t}$, consisting of:

- $\quad$ stud_per_cap - number of students per capita;

$\sum$ CONTROL $_{k, t}$ - vector of control variables of region $\mathrm{k}$ in year $\mathrm{t}$, consisting of:

- grp_per_cap - GRP per capita (USD),

- nex_per_cap - Net export per capita (million USD),

- dens_road - density of automobile roads;

Fixed Effects - fixed effects at the firm level.

As a statistical basis for the study, we used data from the Rosstat for 68 regions of Russia (regions with a smaller number of data were excluded from the sample) for 2001-2014 published in official publications, as well as those contained in electronic databases.

Table 1 below presents the main indicators of descriptive statistics for all variables considered in the model. It is important to note the high standard deviation for all the indicators under study, which points to great differences among Russian companies and among the regions of the Urals Federal District.

\section{Results}

The modelling was done in two steps. First, the overall model has been estimated, then the data was divided into subsets based on the size of the firms. All absolute figures on the regional level are weighed per capita, monetary indicators are presented in real prices. The simulation was performed while taking into account possible heteroscedasticity of the data, the model obtained was tested for multicollinearity.

The results of the modelling are presented in Table 2. They cover both the overall model and models for different size groups. 


Table 1: Descriptive statistics for the statistical indicators used
\begin{tabular}{|l|l|l|l|l|l|}
\hline Variable & Obs. & Mean & Std. dev. & Min. & Max \\
\hline lprod & 27,461 & 8.083655 & 1.665324 & -0.7637597 & 17.22608 \\
\hline lta & 36,932 & 13.28711 & 2.70147 & 2.8778 & 24.88713 \\
\hline import_tec $\sim p$ & 63,060 & 0.9371511 & 2.432529 & 0 & 14.45212 \\
\hline patent_ap_ p & 63,060 & 0.0001832 & 0.0002385 & 0 & 0.0010129 \\
\hline innov_spen $\sim$ p & 63,060 & 5.90713 & 4.387777 & 0.1387058 & 30.48087 \\
\hline innov_share & 63,060 & 10.89624 & 2.690453 & 4.2 & 15 \\
\hline lloc2 & 36,723 & 188.9035 & 155.5219 & 0 & 662.8884 \\
\hline core & 59,834 & 0.148235 & 0.314397 & 0 & 1 \\
\hline stud_per_cap & 63,060 & 0.0500153 & 0.0247062 & 0.0048689 & 0.1277694 \\
\hline grp_per_cap & 63,060 & 345.199 & 349.847 & 68.20414 & 2673.738 \\
\hline nex_per_cap & 63,060 & 5876.9 & 11041.53 & -872.6103 & 43205.09 \\
\hline dens_road & 63,060 & 88.78289 & 46.71325 & 1.4 & 194.7006 \\
\hline Source: authors' estimates on Rosstat regional data and Ruslana firm data \\
\hline
\end{tabular}

Table 2: Results of the econometric estimation

Dependent variable: Labor productivity of the firm

\begin{tabular}{|c|c|c|c|c|c|c|}
\hline & Overall & Micro & Small & Medium & Large & Very Large \\
\hline \multirow{2}{*}{ lta } & $0.339 * * *$ & 0.172 & $0.159 * *$ & $0.284 * * *$ & $0.319^{* * *}$ & $0.388^{* * *}$ \\
\hline & $(-0.007)$ & $(-0.204)$ & $(-0.058)$ & $(-0.013)$ & $(-0.012)$ & $(-0.013)$ \\
\hline \multirow{2}{*}{ import_tec $\sim p$} & $0.027 * * *$ & -0.077 & 0.027 & $0.056 * * *$ & $0.026 * * *$ & $0.023 * * *$ \\
\hline & $(-0.004)$ & $(-0.504)$ & $(-0.07)$ & $(-0.01)$ & $(-0.008)$ & $(-0.006)$ \\
\hline \multirow{2}{*}{ patent_ap_ p } & $406.870 * * *$ & 27.987 & $902.325 * *$ & $429.875 * * *$ & $455.470 * * *$ & $276.812 * * *$ \\
\hline & $(-33.612)$ & $(-429.608)$ & $(-280.587)$ & $(-67.032)$ & $(-57.474)$ & $(-52.213)$ \\
\hline \multirow{2}{*}{ innov_spen $\sim p$} & $-.0168 * * *$ & -0.016 & $-0.062 *$ & $-0.025 * * *$ & $-0.028 * * *$ & -0.007 \\
\hline & $(-0.003)$ & $(-0.068)$ & $(-0.031)$ & $(-0.006)$ & $(-0.005)$ & $(-0.004)$ \\
\hline \multirow{2}{*}{ innov_share } & $-0.042 * * *$ & -0.101 & 0.044 & 0.011 & $-0.044 * * *$ & $-0.073 * * *$ \\
\hline & $(-0.005)$ & $(-0.078)$ & $(-0.052)$ & $(-0.01)$ & $(-0.008)$ & $(-0.008)$ \\
\hline \multirow{2}{*}{11 oc2 } & $-0.001 * * *$ & 0.004 & 0.001 & -0.001 & -0.001 & $-0.001 * * *$ \\
\hline & $(0.000)$ & $(-0.002)$ & $(-0.001)$ & $(0.000)$ & $(0.000)$ & $(0.000)$ \\
\hline \multirow{2}{*}{ core } & $1.1792 * * *$ & 3.645 & 0.029 & $0.622 * * *$ & $0.909 * * *$ & $1.887 * * *$ \\
\hline & $(-0.086)$ & $(-1.886)$ & $(-1.483)$ & $(-0.156)$ & $(-0.14)$ & $(-0.154)$ \\
\hline \multirow{2}{*}{ stud_per_cap } & $-7.866 * * *$ & 1.270 & 25.159 & $9.219 * *$ & $-5.190^{*}$ & $-18.709 * * *$ \\
\hline & $(-1.351)$ & $(-36.073)$ & $(-13.363)$ & $(-2.882)$ & $(-2.237)$ & $(-2.077)$ \\
\hline \multirow{2}{*}{ grp_per_cap } & $0.001 * *$ & 0.001 & -0.002 & 0.001 & 0.0002 & $0.0003^{* *}$ \\
\hline & $(0.000)$ & $(-0.006)$ & $(-0.002)$ & $(0.000)$ & (0.000) & $(0.000)$ \\
\hline \multirow{2}{*}{ nex_per_cap } & $-0.00001 * * *$ & $-1.91 \mathrm{e}-05$ & $-7.75 e-09$ & $-9.77 \mathrm{e}-06^{*}$ & $-0.00002 * * *$ & $-0.00002 * * *$ \\
\hline & $(0.000)$ & $(0.000)$ & $(0.000)$ & $(0.000)$ & $(0.000)$ & $(0.000)$ \\
\hline \multirow{2}{*}{ dens_road } & $-.001 *$ & 0.002 & 0.004 & -0.001 & -0.001 & -0.001 \\
\hline & $(0.000)$ & $(-0.007)$ & $(-0.004)$ & $(-0.001)$ & $(-0.001)$ & $(-0.001)$ \\
\hline \multirow{2}{*}{ _cons } & $4.357 * * *$ & 5.081 & $3.567 *$ & $3.548 * * *$ & $4.558 * * *$ & $4.319 * * *$ \\
\hline & $(-0.166)$ & $(-3.284)$ & $(-1.44)$ & $(-0.323)$ & $(-0.271)$ & $(-0.288)$ \\
\hline Obs. & 27108 & 59 & 357 & 7020 & 10272 & 9400 \\
\hline Fixed effects & Yes & Yes & Yes & Yes & Yes & Yes \\
\hline Overall $\mathrm{R}^{\wedge} 2$ & 0.237 & 0.361 & 0.051 & 0.108 & 0.089 & 0.129 \\
\hline
\end{tabular}

Source: authors' estimates on Rosstat regional data

*Significant at 5\%;**Significant at $1 \% ; * * *$ Significant at $0.1 \%$. Standard errors in the parentheses

According to the results of econometric estimation there are significant differences in the effects of innovation when using subsamples.

For the overall model, indicators of innovation activity in the region have an ambiguous impact on the performance of individual firms in the sample. Indicators such as the number of patent applications or the volume of technology imports have a significant positive impact on productivity, while the other two innovative indicators have a negative impact. Such results can confirm the ineffectiveness of the innovation policy pursued for enterprises in general and point out the need for specialization of policies on a sectoral basis. It is important to note that the import of technologies has a positive impact. This fact highlights the importance of stimulating the import of innovations as a first step towards innovative development. The negative impact of the share of innovative enterprises may 
confirm the fact that overcrowding of innovative firms in the same area may result in negative effects on all firms in the area. At the same time, it may indicate that the absorptive capacity level is so low for the UFD companies that they cannot adapt to new technologies without spending a large portion of their resources, which consecutively harms productivity in the sort and medium run.

Spatial effects are also found to be significant at a high level. The 'Core' indicator has a positive effect, and the localization index is negative. In our opinion, such a result can testify to two important features of the Russian economy. First, it can be an argument in favor of the development of specialized cities and regional clusters. Secondly, the negative value of the localization index shows that in the UFD cities, that take the largest share of the settlement types considered, with a high localization rate there are factors that limit the growth of productivity of enterprises, which can be expressed in excessive competition, protracted bureaucratic procedures and other institutional factors and general overcrowding.

The control variables are significant and have the expected effects. The negative effects of net exports is due to the fact that the main exported goods in Russia and the UFD are natural resources produced by industries with low labor productivity.

To obtain more accurate results, modeling of the effects of innovation and spatial effects was carried out on the basis of subsamples divided by the firm size. A second stage of modelling indicates, on the one hand, the similar results for spatial effects, and on the other, the presence of significant differences in the effects of innovation across subsets.

The results of this stage of modelling follow the general logic that small firms tend to feel only a weak influence from external factors, as they are oriented towards an extremely small or local market. For these firms, the most significant indicator in the model is the indicator of the company's total assets. For medium and larger firms, the impact is more significant. In particular, for all medium-sized firms, all the indicators used were significant; and for other sizes - most significant. There are positive effects from the spending on innovation, the share of innovative companies in the region and patent applications. The strongest effect of spending on innovation is observed in very large enterprises. The effects of spatial indices are similar to those obtained in the overall model. Such a result may indicate that innovation policy should first of all be directed to larger enterprises, with financial support instruments that are of greatest benefit to very large companies, and for innovative medium and large companies the innovative climate in the region where they operate is more important.

In the course of the study of subsamples, significant differences in the effects of the investigated indicators between the sizes of the firms were revealed. These differences should be taken into account when forming an innovation policy aimed at increasing the competitiveness of Russian enterprises. At the same time, there was a negative impact of the number of students on the productivity of firms in all of the subsets, which confirms the thesis about the inability of Russian higher education to meet production needs, the discrepancy between the qualifications received during training and the qualifications needed for the production and innovation process.

\section{Conclusion}

To sum up, it is worth noting a low share of not only high-tech industries in the UFD, but also innovation-active enterprises in general. This situation is, unfortunately, typical for Russia as a whole, on top of that the relatively low productivity of the Ural companies is observed (Kuznetsov, 2015).

The main results of this paper are as follows. On average, for firms in the Urals Federal District, innovations and an innovative climate have a significant impact on the performance of companies. Nevertheless, the results obtained for the individual indicators are ambiguous. There is a positive effect of technology imports and the number of patent applications per capita, while the costs of innovation and the number of innovative companies in the region have a negative impact on the logarithm of productivity. Such results may be due to the fact that at the moment in the UFD the level of involvement in the innovation process is relatively low, and the economy is more oriented towards more traditional industrial sectors. This in turn leads to a lack of development of the technological base, without which obtaining positive effects from stimulating the introduction of innovations and a favorable innovation climate in the region is difficult.

Spatial effects demonstrate that in the UFD economy, increased localization is negatively related to productivity, while the "specialization" of cities on the contrary positively affects this indicator. This 
serves as an important argument in favor of creating highly specialized zones, technology parks, and support and modernization of already existing single-industry towns.

As for the individual sizes of firms, the results obtained in the research are to be expected and generally follow the logic of strengthening the influence of external effects with the increase in the size of the firm. Thus, in order to obtain the greatest return in increasing the productivity of firms, innovation policy should be directed first and foremost to large and very large enterprises.

The presented study may be expanded with a modification of the proposed econometric model, since the constructed models have a relatively low R-squared coefficient. In particular, a number of control microeconomic factors affecting productivity can be taken into account; the external effects of human capital, market potential and the indicators of spatial concentration can be extended and tested. An important continuation of the study may be a comparative analysis of the results obtained on similar data from other federal districts of Russia or the regions of other countries, which will make it possible to reveal the patterns described in the work.

In addition, in order to predict the success of the regional innovation policy, a number of simulations using fictitious data can be conducted to assess the impact of the innovative climate and measures to improve it on firm productivity.

\section{Acknowledgements}

This research was supported by the Russian Foundation for Basic Research (RFBR) grant No. 18-01001190 "Models of innovation development factors and comparative advantages analysis in the Russian economy".

\section{References}

Berger, M. (2010). The innovation-productivity link - comparing Thailand with a sample of OECD countries. Fourth Conference on Micro Evidence on Innovation in Developing Economies, 38 p.

Chudnovsky, D., A. Lopez, G. Pupato. (2006). Innovation and productivity in developing countries: A study of Argentine manufacturing firms' behavior (1992-2001). Research Policy, Vol. 35, pp. 266-288.

Crepon, B., E. Duguet, and J. Mairesse. (1998) Research, Innovation and Productivity: An Econometric Analysis at the Firm Level. Economics of Innovation and New Technology, Vol. 7, 2, pp. 115-58.

Duguet E. (2006). Innovation height, spillovers and tfp growth at the firm level: Evidence from French manufacturing. Economics of Innovation and New Technology, Vol. 15(4-5), pp. 415-442.

Fritsch M., Aamoucke R. (2013). Regional public research, higher education, and innovative start-ups: an empirical investigation // Small Business Economics, Vol. 41, pp. 865-885.

Griffith, R. et al. (2006). Innovation and Productivity across Four European Countries. Oxford Review of Economic Policy, Vol. 22, Issue 4, pp. 483-498.

Griliches, Z. (1979). Issues in Assessing the Contribution of Research and Development to Productivity Growth. Bell Journal of Economics, Vol. 10(1), pp. 92-116

Janz, N., Lööf, H., Peters, B. (2004). Firm Level Innovation and Productivity - Is there a Common Story Across Countries. Problems and Perspectives in Management, No. 2., 22 p.

Kuznetsov E.B. (2015). National report on innovations in Russia 2015. Moscow: Ministry of Economic Development of the Russian Federation, 146 p.

Lööf, H. and Heshmati., (2006). On the Relationship Between Innovation and Performance: a Sensitivity Analysis // Economics of Innovation and New Technology, Vol. 15, Issue 4-5, pp. 317-344.

Mariev, O. S., Shorokhova, I. S. (2011). Instituty innovatsionnoy politiki: mirovoy opyt i rossiyskiye osobennosti [Institutes of Innovation Policy: World Experience and Russian Features]. Journal of Economic Theory, No. 2, pp. 149-152.

Masso, J. and P. Vahter. (2008). Technological innovation and productivity in late-transition Estonia: econometric evidence from innovation surveys. The European Journal of Development Research, Vol. 20, Issue 2, pp. 240-261.

Pavitt, K. (1984) Sectoral patterns of technical change: towards a taxonomy and a theory. Research Policy, Vol. 13, pp. 343373.

Raffo, J., S. Lhuillery and L. Miotti. (2008). Northern and Southern Innovativity: A Comparison across European and Latin American Countries. European Journal of Development Research, Vol. 20(2), pp. 219-239.

Solow, R.M. (1957). Technical Change and the Aggregate Production Function. The Review of Economics and Statistics, Vol. 39, No. 3, pp. 312-320.

Zhang, H. (2015). How does agglomeration promote the product innovation of Chinese firms? China Economic Review, Vol. 35 , pp. 105-120. 